Article

\title{
Social determinants and access to Water-Sanitation-Hygiene as dominant risk factors of stunting among under-five children in rural area of East Indonesia
}

\author{
Dini Suciyanti ${ }^{1}$, Grace Wangge ${ }^{1}$, Elisa Iskandar², Umi Fahmida ${ }^{1}$, Taniawati Supali ${ }^{2}$ \\ 1 Southeast Asian Ministers of Education Organization Regional Centre for Food and Nutrition (SEAMEO \\ RECFON)/ Pusat Kajian Gizi Regional - Universitas Indonesia, Jakarta, Indonesia; information@seameo- \\ recfon.org \\ 2 Department of Parasitology, Faculty of Medicine, Universitas Indonesia, Jakarta, Indonesia; \\ humas@fkui.ac.id \\ * Correspondence: g.wangge@seameo-recfon.com
}

\begin{abstract}
Background: Stunting remains a challenge in Indonesia, where $30.8 \%$ of under-five children are stunted and may never reach full potential height and cognitive function. We aimed to investigate the risk factors of stunting in Nangapanda subdistrict, East Nusa Tenggara; (2) Methods: The design was cross-sectional study located in rural area as part of PINTERMIDI UI project. We collected quantitative data on social determinants, weight, height, hemoglobin, ferritin, serum zinc, CRP, worm infection, history of deworming, co-morbidity, food security, and nutrient intake; (3) Results: A total of 196 under-five children included and 74\% households were food insecure. The prevalence of stunting was $29.9 \%$ in this population $31.8 \%$ worm infection, $30.3 \%$ iron deficiency, and $28.1 \%$ zinc deficiency). Multivariate analysis showed household with 5-8 members (AOR 3.076; 95\% CI 1.132 - 8.356) and unsafe drinking water (AOR 1.702; 95\% CI 0.825-3.512) were significant independent risk factors of stunting after adjusted by child's gender, father's occupation, caregiver's education, monthly expenses, sanitary facilities, and food security status; (4) Conclusions: The number of household members is the only independent risk factor of stunting among children age 24-59 months in rural area of Eastern Indonesia. Development of nutrition sensitive intervention and promotion of family planning are needed in order to increase adequate child's care and feeding practices in rural area of Eastern Indonesia.
\end{abstract}

Keywords: rural; stunting; household size, Indonesia

\section{Introduction}

Indonesia is the world's fourth largest population and will be facing "bonus demography" in 2045. Unfortunately, child malnutrition is still high[1] while economy grow and poverty reduce significantly in the last decade[2]. Stunting is the most prevalent child malnutrition in worldwide. It was observed that stunting is determined by geopolitics, economics, inadequate diet, and endemic diseases[3]. World Health Organization invented that length-for-age score falters dramatically to 24 months of age[4]. When a girl or boy becomes stunted, the linear growth and the essential organs do not reach its potential. In the long run, stunting has an impact on increasing the risks of obesity 
and degenerative diseases, lowering academic performance, and decreasing work capacity[5].

Over one-third (30.8\%) under-five children were stunted in 2018[1]. This prevalence is even higher among poor households and who is living in rural areas in Indonesia[6-9]. Previous study in three different typologies in Indonesia highlighted the association between stunting and living standards might be explained by food insufficiency, worse sanitation, untreated water, limit access to health facilities, and other health-related behaviors[10]. In fact, children living in rural areas and outside of Java are more likely to be stunted[8,11].

PINTERMIDI UI is a multi-disciplinary study on stunting and its associations with gut and oral health, cognition, WASH (water, sanitation, and hygiene), and socio-culture in rural children. This is a follow-up from previous study in Ende which was performed in 2013. East Nusa Tenggara is one of the most neglected regions where face several problems such as poverty, extreme drought, water crisis, infectious diseases, food insecurity, and high prevalence of malnutrition. As much as $42.7 \%$ under-five children were stunting in East Nusa Tenggara[1] even much higher than national prevalence. The previous study found that only child age remained a significant determinant for stunting among children age 1259 months after adjusting for potential confounders, such as children's gender, maternal education, worm infection, maternal anemia, and breasfeeding status[12]. However, nationally representative robust data are still lacking to determine the risk factors of stunting among children age 24-59 months. A better understanding of the stunting factors among under-five children in East Nusa Tenggara would assist to optimize the local strategies to tackle child malnutrition problem. Here we sought to investigate the risk factors of stunting in Nangapanda subdistrict, East Nusa Tenggara, Indonesia. Therefore, this study aims to describe the risk factors and determinants factors of stunting among children age 24-59 months in rural area of Eastern Indonesia.

\section{Materials and Methods}

\subsection{Study Population}

The sample size was estimated based on the prevalence of stunting and anemia among under-five obtained by our group among children in another rural area (Sambas district), Indonesia in 2017 (Data not published). In this study, the error level of type $1(\alpha) 5 \%$ and power $80 \%$ was used.

Participants were recruited on the basis of the following inclusion criteria: 1) age 2459 months; 2) apparently healthy and 3) received consent by the parents or the caregivers. A list of children was obtained by Public Health Center. It was then purposively selected if they met inclusion criteria. Exclusion criteria were: 1) in the occurrence of illness at data collection time; 2) had serious or chronic condition diagnosed by medical doctor; 3 ) parents were unable to provide consent. Each participant was provided with full information about the study. Written inform consent was obtained from all participants agree to participate. This study received ethical approval from Health Research Ethics Committe, Faculty of Medicine, Universitas Indonesia-Cipto Mangunkusumo Hospital (Reference No: KET- 
1060/UN2.F1/ETIK/PPM.00.02/2019). Permission from the local government was obtained to conduct the field data collection.

\subsection{Study Design and Setting}

The study design was cross-sectional study located in rural area, Nangapanda subdistrict, Ende, East Nusa Tenggara, Indonesia as a part of PINTERMIDI UI project. The data were obtained from 24 villages in selected subdistrict that covers coastal and upper land area.

\subsection{Data Collection}

Data collection was performed in October 2019. We trained local enumerators during two days before data collection. The standard questionnaires were pretested prior to implementation in the field and pilot survey was also conducted. We collected data on social determinants characteristics, anthropometric assessments, co-morbidity, history of deworming, WASH, food security status and nutrient intake. Biochemical measurements (serum ferritin, serum zinc, serum C-Reactive Protein) and parasitical examination were performed in sub-sample ( \pm 100 subjects). Field coordinators were assigned to supervise enumerators collecting complete questionnaires in the field. Quality assurance steps were also considered during data entry and cleaning.

\subsection{Interview Structured Questionnaires}

The social determinants data included children's age and gender, parent's education and occupation, family household size, monthly expenses, and housing situation. The level of education was defined as years of education completed: 1) low (never went to school to junior high school graduates); 2) middle (graduated from senior high school); 3) high (graduated from diploma/bachelor degree and beyond). The type of occupation was grouped as 1) formal (public/private employee/Indonesian migrant worker); 2) semiformal (farmer/fisherman/seller/labor/self-employed, etc.); 3) not working (retired/not working). The number of household member was divided into 1) $\leq 4$ members; 2) 5-8 members; 3) $\geq$ 9 members. Monthly expenses was ascertained by computing the money quintiles and was grouped as 1) lowest tertile (< IDR 646.500); 2) middle tertile (IDR 646.500 - 1.394.000) highest tertile (> IDR 1.394.000). Dwelling status, location, and source of electricity were indicators of housing situation and were assessed via spot-checked observations by survey enumerators. Dwelling status was categorized as 1) private; 2) parent/relatives; 3) rent. The location of house was determined close to: 1) forest; 2) beach; 3) stockbreeding; 4) garden. Source of electricity was defined whether household used national electricity or not.

We recorded co-morbidity data by the occurrence of upper respiratory tract infection, fever, and diarrhea in last two weeks and measles in last six months as self-reported by caregivers. In addition, we identified the occurrence of worm infection (from mouth or feces) and history of received deworming in last one year. The indicators of WASH (water, sanitation, and hygiene) were source of drinking water, sanitary facility, and mother/caregiver's personal hygiene. We defined source of drinking water as 1) safe (tube well/ piped water); 2) unsafe (mineral water/ refill water/ well spring/ surface water/ 
rainwater/ water shelter)[13]. For sanitary facility, we observed whether household had: 1) private latrine; 2) public latrine; 3) no facility. Mother/caregiver's personal hygiene was self-reported whether they take handwash: 1) before food preparation; 2) before eat; 3 ) before feeding the children; 4) after from toilet; 5) after children's bathing. Food security was identified using the standard household food insecurity access scale in last month developed by Food and Nutrition Technical Assistance (FANTA) project[14]. It was then categorized as food secure and food insecure.

\subsection{Dietary Assessments}

Dietary intake was estimated by using the first 24-h food recall for all samples and the second 24-h food recall for sub samples in order to obtain the percentage of nutrient adequacy in this population. We provided Indonesian food picture book to estimate the children's consumption. The dietary data was then inputted to Nutrisurvey software and was analyzed using MSM (Multiple Source Method) program to estimate usual intake of nutrients[15]. The Estimated Average Requirement (EAR) was used to categorize as[16]: 1) adequate (nutrient intake $\geq E A R$ ); 2) inadequate (nutrient intake $<$ EAR) for mineral (calcium, iron, zinc) and vitamin (A, B1, B2, B3, folate, B12, C).

\subsection{Anthropometric Measurements}

The survey employed trained anthropometric staff to ensure data quality with respect to the all the procedures and survey activities. Weight was measured using SECA weight scale and height was measured by Shorr-board. The weight scale was calibrated daily for any possible errors. The data was then calculated height for age z-score (HAZ-score) and weight for age z-score (WAZ) by using WHO Anthro software[17]. Stunting defined as HAZ-score of $<-2$ and underweight defined as WAZ-score of $<-2$ based on the WHO Child Growth Standards [18].

\subsection{Biochemical Measurements}

Trained laboratory analyst obtained venous blood from the children using single-use sterile syringe and placed the blood in a red top microtainer. We used Hemocue $\mathrm{Hb} 201+$ that needs disposable microcuvatte to measure hemoglobin levels in a drop of blood samples after 5 hours of blood collection. Hemocue was calibrated daily for any possible errors. Anemia defined as hemoglobin $<11 \mathrm{mg} / \mathrm{dL}[19]$. The blood was centrifuged approximately 5 hours after blood collection. Serum was then transported to Jakarta and was stored at $-20^{\circ} \mathrm{C}$ for analysis of zinc, ferritin, and C-Reactive Protein (CRP) in Laboratory of SEAMEO RECFON. To evaluate zinc deficiency, we used serum zinc analysis using Atomic Absorption Spectrophotometry (AAS). Serum zinc concentrations was then adjusted for CRP to consider inflammation response[20]. Zinc deficiency defined as serum zinc $<9.9 \mu \mathrm{mol} / \mathrm{L}[21]$. Serum ferritin were measured using Fluorescence Enzyme Immunoassay (FEIA) for iron deficiency identification. The ferritin concentrations was adjusted for CRP to consider that ferritin is an acute phase protein and is raised in inflammatory conditions[22]. Iron deficiency defined as serum ferritin $<12 \mathrm{mg} / \mathrm{dL}[23]$. 
Serum CRP was analyzed using Immunoassay CLEIA. Subclinical inflammation was then identified if serum CRP $>5 \mathrm{mg} / \mathrm{L}$ and serum ferritin 12-30 mg/dL [22].

\subsection{Parasitical Examinations}

A single stool sample was collected from each child using a stool container. Kato-Katz is the most widely used microscopy technique to detect a soil-transmitted helminth (STH) species and to quantify the infection[24]. A single Kato-Katz smear was used to identify eggs and larvae of helminths. A $41.7 \mathrm{mg}$ template was placed on the microscopy slide and filled with sieved stool material. The sample was covered then with a cellophane slip soaked with glycerol and water. After that, the sample was flattened by pressing it. The slide has to be examined under the microscope within 30-60 minutes after preparation. In addition, the microscopic examination of protozoan cysts was measured using direct smear technique with lugol staining. These two examinations were performed on the same day as stool sample collected. The remaining sample was aliquoted into several tubes and was transported to Laboratory of Parasitology Universitas Indonesia in Jakarta and was stored at $-20^{\circ} \mathrm{C}$ for others analysis. Positive worm infection was identified if we found one of the three STH species that are Ascaris Lumbricoides, hookworm, and whipworm.

\subsection{Statistical Analysis}

Data analysis was conducted using SPPS version 20. First, univariate analysis was used to summarize descriptive data. Second, chi-square and Fisher test was performed to analyze the association between stunting and each of risk factors. Pearson or Spearman correlation was used to analyzed the continues data (HAZ-score, serum zinc, serum ferritin, hemoglobin, zinc intake). Third, variables at OR > 1.5 in all samples $(n=196)$ were selected to be included in the multivariate model. Logistic regression was then used to assess determinants of stunting with adjusted odd ratios (AOR) and 95\% confident intervals (CI) for variables.

\section{Results}

\subsection{Characteristics of Respondents}

A total of 196 children between the ages of 24-59 months were identified that boys was more than girls (Table 1). The prevalence of stunting and zinc deficiency in Nangapanda subdistrict were $29.9 \%$ and $40.9 \%$, respectively. As much as $31.7 \%$ and $21.1 \%$ children suffered from anemia and iron deficiency. The number of under-five with worm infected was 19 out of 100 children. Moreover, it was interesting to note that $2 \%$ and $24 \%$ caregivers reported that their child ever worm infected by the mouth and feces, respectively. In last one year, $45.4 \%$ children received deworming program. Two weeks prior to data collection, $63.8 \%$ of respondents experienced in upper respiratory tract infection.

Table 1. Description of characteristics of respondents

\begin{tabular}{ll}
\hline Variables & n (\%) \\
\hline Children's age &
\end{tabular}




\begin{tabular}{|c|c|}
\hline Variables & n (\%) \\
\hline 36-59 months & $94(48)$ \\
\hline \multicolumn{2}{|l|}{ Children's gender } \\
\hline Boys & $111(56.6)$ \\
\hline Girls & $85(43.4)$ \\
\hline Stunting & $58(29.9)$ \\
\hline Underweight & $51(26.3)$ \\
\hline Zinc deficiency & $38(40.9)$ \\
\hline Anemia & $52(31.7)$ \\
\hline Iron deficiency & $20(21.1)$ \\
\hline Subclinical inflammation & $14(14)$ \\
\hline Worm infection & $19(19)$ \\
\hline History of deworming & $89(45.4)$ \\
\hline \multicolumn{2}{|l|}{ Co-morbidity } \\
\hline Upper respiratory tract infection & $125(63.8)$ \\
\hline Diarrhea & $4(2)$ \\
\hline Fever & $46(23.5)$ \\
\hline Measles & $4(2)$ \\
\hline \multicolumn{2}{|l|}{ Father's occupation } \\
\hline Formal & $44(23.2)$ \\
\hline Semiformal & $143(75.3)$ \\
\hline Not working & $3(1.6)$ \\
\hline \multicolumn{2}{|l|}{ Caregiver's education } \\
\hline Low level education & $95(50.5)$ \\
\hline Middle level education & $55(29.3)$ \\
\hline High level education & $38(20.2)$ \\
\hline \multicolumn{2}{|l|}{ Family household size } \\
\hline$\leq 4$ members & $48(24.5)$ \\
\hline 5-8 members & $126(64.3)$ \\
\hline$\geq 9$ members & $22(11.2)$ \\
\hline \multicolumn{2}{|l|}{ Monthly expenses (IDR)* } \\
\hline Lowest tertile & $49(25)$ \\
\hline Middle tertile & $101(51.5)$ \\
\hline Highest tertile & $46(23.5)$ \\
\hline \multicolumn{2}{|l|}{ Family house dwelling status } \\
\hline Private & 155 (79.1) \\
\hline Parents/relatives & $40(20.4)$ \\
\hline Rent & $1(0.5)$ \\
\hline \multicolumn{2}{|l|}{ Location of family house } \\
\hline Forest & $6(3.1)$ \\
\hline Beach & $21(10.7)$ \\
\hline Stockbreeding & $32(16.3)$ \\
\hline
\end{tabular}




\begin{tabular}{lc}
\hline Variables & $\mathbf{n}(\mathbf{\%})$ \\
\hline Garden & $62(31.6)$ \\
Source of electricity of family house & $196(100)$ \\
$\quad$ National Electricity & \\
Water, Sanitation, and Hygiene (WASH) & \\
Source of drinking water & $131(66.8)$ \\
$\quad$ Safe drinking water & $65(33.2)$ \\
$\quad$ Unsafe drinking water & \\
Sanitary facilities & $172(89.6)$ \\
$\quad$ Private latrine & $15(7.8)$ \\
Public latrine & $5(2.6)$ \\
$\quad$ No facility & \\
Personal hygiene & $157(80.1)$ \\
$\quad$ Before food preparation & $161(82.1)$ \\
Before eat & $152(77.6)$ \\
Before feeding the children & $174(88.8)$ \\
After taking toilet & $175(89.3)$ \\
After washing the children & \\
Food security status & $145(74)$ \\
Food insecure & $51(26)$ \\
Food secure &
\end{tabular}

As shown in Table 1, semiformal sector was the majority of occupation owned by respondent's fathers (75.3\%). A half of caregivers had low level of education. Overall, $64.3 \%$ children were living with families with 5-8 members per household. They lived, mainly in private house with tin's roof and cement's floor. The house location was closed to garden $(31.6 \%)$ and stockbreeding $(16.3 \%)$. All of community had access to national electricity network.

It was observed that $33.2 \%$ households did not have access to safe drinking water. Only $7.8 \%$ households used public latrine and $2.6 \%$ had no latrine facility. More than $75 \%$ caregivers had good personal hygiene. However, $90.2 \%$ of them used pooled water to wash their hands. In terms of food security, $74 \%$ households were food insecure. According to nutrient intake analysis, most of vitamin (B1, B2, B3, Folate, C) and mineral (Calcium, Iron, Zinc) intake were inadequate, except for vitamin A and B12 (Supplementary Table).

Table 2. The association between serum zinc, serum ferritin, hemoglobin, zinc intake and HAZ-score in under-five children

\begin{tabular}{lcc}
\hline Variables & Mean \pm SD/ Med (25th, 75th) & p-value \\
\hline Serum zinc $^{1}$ & $10.35 \pm 1.96$ & 0.756 \\
Serum ferritin $^{2}$ & $19.9(13.5,31.3)$ & $0.007^{*}$ \\
Hemoglobin $^{2}$ & $11.4(10.8,12.07)$ & 0.11 \\
Zinc intake $^{2}$ & $1.9(1.7,2.3)$ & $\mathrm{p}=0.252$ \\
\hline
\end{tabular}

${ }^{1}$ Pearson correlation test 
${ }^{2}$ Spearman correlation test

By using Pearson or Spearman correlation, we observed that only serum ferritin had strong correlation with HAZ-score $(p<0.0001)$. The mean or median of serum zinc, serum ferritin, and hemoglobin are normal. Respectively, the median intake of zinc is still under the EAR.

\subsection{Bivariate and Multivariate Analysis between several factors and stunting}

From bivariate analysis (Table 3), we found the older children (36-59 months) had more likely to be stunted than the younger children (OR 2.109; 95\% CI 1.127 - 3.947). Suprisingly, underweight children had 21 times risks to be stunted and followed by iron deficiency (OR 2.174; 95\% CI 0.795 - 5.945) and also positive worm infection (OR 2.528; 95\% CI $0.851-7.505)$. According to social determinants, it showed that father's occupation (OR 6.800; 95\% 0.557 - 82.995), caregiver's education (OR 1.871; 95\% CI 0.767 - 4.563), family household size (OR 2.654; 95\% CI 1.141 - 6.175), and monthly expenses (OR 1.724; 95\% CI 0.761 - 3.903) were contributed to the occurrence of stunting children. From WASH indicators, it was clear that children living with family who consumed unsafe drinking water (OR 1.818; 95\% CI 0.961 - 3.439) and had no sanitary facility in their house (OR 1.646; $95 \%$ CI 0.267 - 10.158) were more likely to be stunted. Furthermore, we pointed out that the odds of being stunted children were 1.5 times higher in food insecure families.

Further analysis used logistic regression to investigate determinants of stunting in this study. We revealed an increased odds ratio of household with 5-8 members (AOR 3.076; $95 \% \mathrm{Cl} 1.132$ - 8.356) after adjusted by child's gender, father's occupation, caregiver's education, monthly expenses, sanitary facilities and food security status. However, there was a slight decrease in odds ratio of unsafe drinking water (AOR 1.702; 95\% Cl $0.825-$ 3.512) but still above 1.5 point. 
Table 3. Bivariate and multivariate analysis of stunting determinants

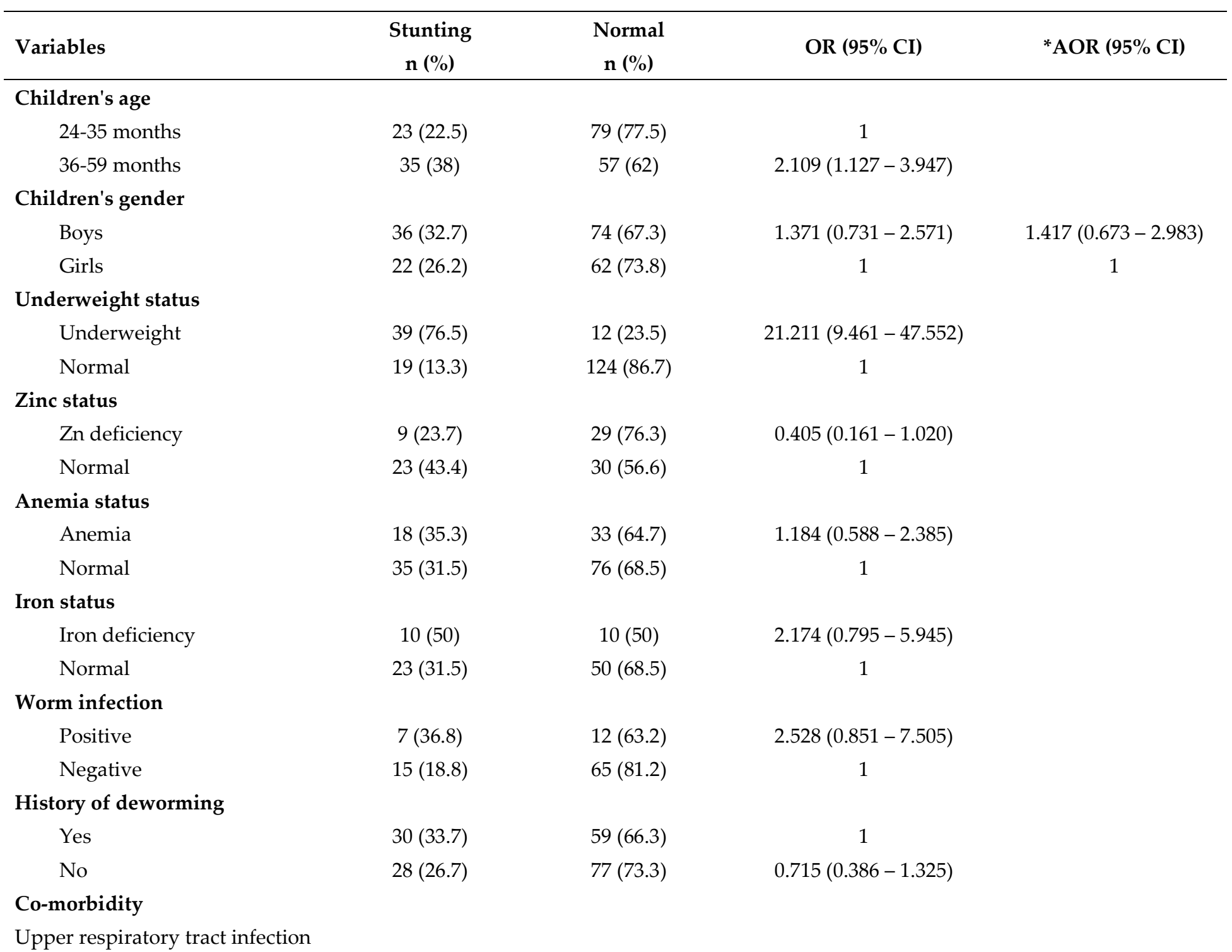

Upper respiratory tract infection 
10 of 15

\begin{tabular}{|c|c|c|c|c|}
\hline Variables & $\begin{array}{c}\text { Stunting } \\
\text { n (\%) }\end{array}$ & $\begin{array}{c}\text { Normal } \\
\text { n (\%) }\end{array}$ & OR $(95 \% \mathrm{CI})$ & ${ }^{*} \mathrm{AOR}(95 \% \mathrm{CI})$ \\
\hline Yes & $36(29)$ & $88(71)$ & $0.893(0.472-1.687)$ & \\
\hline No & $22(31.4)$ & $48(68.6)$ & 1 & \\
\hline \multicolumn{5}{|l|}{ Diarrhea } \\
\hline Yes & $0(0)$ & $4(100)$ & $1.439(0.310-1.582)$ & \\
\hline No & $58(30.5)$ & $132(69.5)$ & 1 & \\
\hline \multicolumn{5}{|l|}{ Fever } \\
\hline Yes & $10(22.2)$ & $35(77.8)$ & $0.601(0.275-1.314)$ & \\
\hline No & $48(32.2)$ & $101(67.8)$ & 1 & \\
\hline \multicolumn{5}{|l|}{ Measles } \\
\hline Yes & $0(0)$ & $4(100)$ & $1.439(1.310-1.582)$ & \\
\hline No & $58(30.5)$ & $132(69.5)$ & 1 & \\
\hline \multicolumn{5}{|l|}{ Father's occupation } \\
\hline Formal & $10(22.7)$ & $34(77.3)$ & 1 & 1 \\
\hline Semiformal & $42(29.8)$ & $99(70.2)$ & $1.442(0.653-3.185)$ & $1.173(0.434-3.175)$ \\
\hline Not working & $2(66.7)$ & $1(33.3)$ & $6.800(0.557-82.995)$ & $5.292(0.353-79.280)$ \\
\hline \multicolumn{5}{|l|}{ Caregiver's education } \\
\hline Low level education & $32(34)$ & $62(66)$ & $1.871(0.767-4.563)$ & $1.472(0.494-4.391)$ \\
\hline Middle level education & $14(25.5)$ & $41(74.5)$ & $1.238(0.460-3.332)$ & $1.177(0.378-3.667)$ \\
\hline High level education & $8(21.6)$ & $29(78.4)$ & 1 & 1 \\
\hline \multicolumn{5}{|l|}{ Family household size } \\
\hline$\leq 4$ members & $8(16.7)$ & $40(83.3)$ & 1 & 1 \\
\hline 5-8 members & $43(34.7)$ & $81(65.3)$ & $2.654(1.141-6.175)$ & $3.076(1.132-8.356)$ \\
\hline$\geq 9$ members & $7(31.8)$ & $15(68.2)$ & $2.333(0.720-7.557)$ & $3.287(0.880-12.283)$ \\
\hline \multicolumn{5}{|l|}{ Monthly expenses (IDR) } \\
\hline Lowest tertile & $15(30.6)$ & $34(69.4)$ & $1.544(0.610-3.910)$ & $0.962(0.334-2.773)$ \\
\hline Middle tertile & $33(33)$ & $67(67)$ & $1.724(0.761-3.903)$ & $1.502(0.628-3.592)$ \\
\hline
\end{tabular}




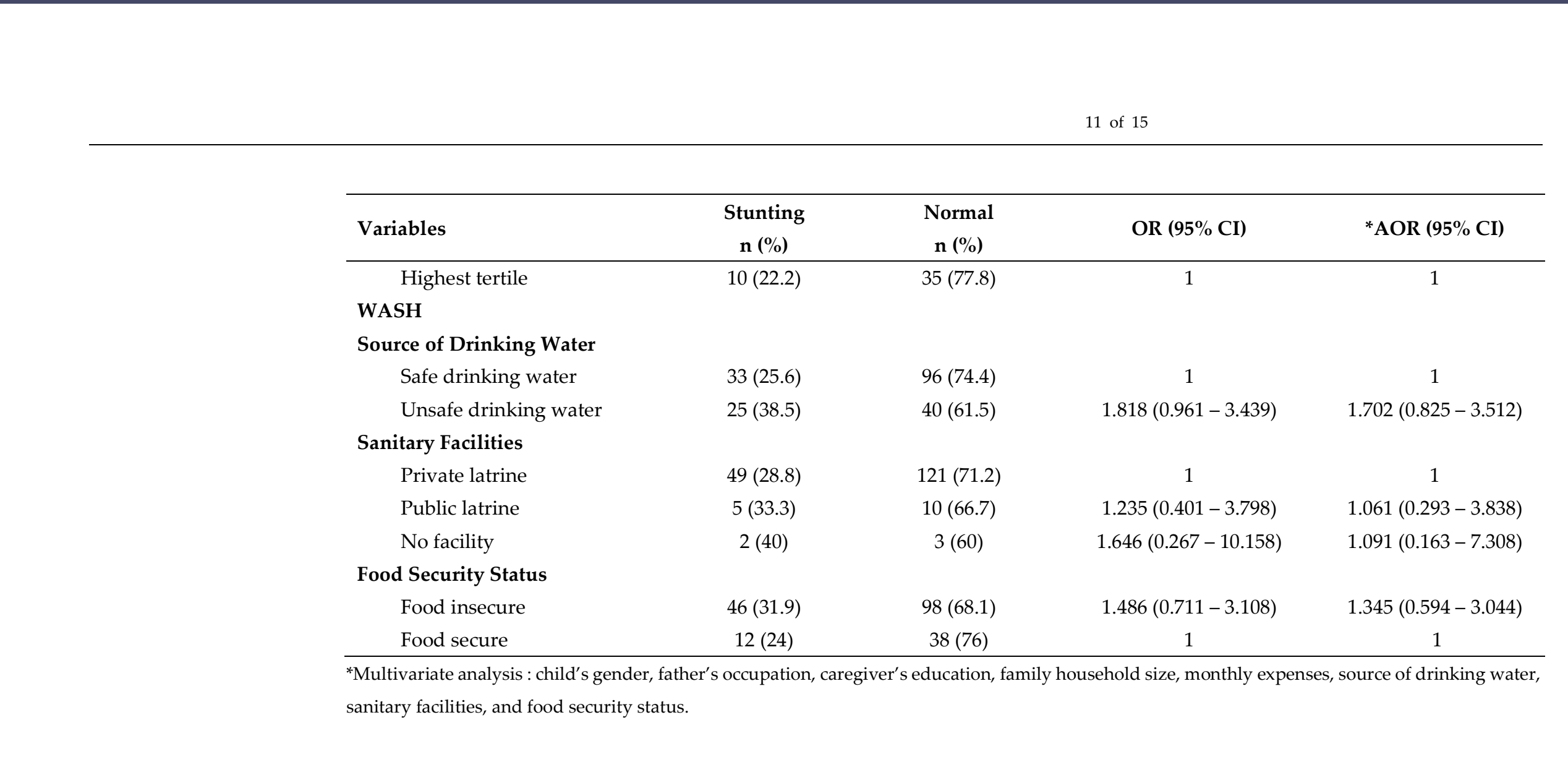

*Multivariate analysis : child's gender, father's occupation, caregiver's education, family household size, monthly expenses, source of drinking water, sanitary facilities, and food security status. \\ doi:10.20944/preprints202107.0279.v1}

\begin{tabular}{|c|c|c|c|c|}
\hline Variables & $\begin{array}{c}\text { Stunting } \\
\text { n (\%) }\end{array}$ & $\begin{array}{c}\text { Normal } \\
\text { n (\%) }\end{array}$ & OR $(95 \%$ CI $)$ & ${ }^{*} \mathrm{AOR}(95 \% \mathrm{CI})$ \\
\hline Highest tertile & $10(22.2)$ & $35(77.8)$ & 1 & 1 \\
\hline \multicolumn{5}{|l|}{ WASH } \\
\hline \multicolumn{5}{|l|}{ Source of Drinking Water } \\
\hline Safe drinking water & $33(25.6)$ & $96(74.4)$ & 1 & 1 \\
\hline Unsafe drinking water & $25(38.5)$ & $40(61.5)$ & $1.818(0.961-3.439)$ & $1.702(0.825-3.512)$ \\
\hline \multicolumn{5}{|l|}{ Sanitary Facilities } \\
\hline Private latrine & $49(28.8)$ & $121(71.2)$ & 1 & 1 \\
\hline Public latrine & $5(33.3)$ & $10(66.7)$ & $1.235(0.401-3.798)$ & $1.061(0.293-3.838)$ \\
\hline No facility & $2(40)$ & $3(60)$ & $1.646(0.267-10.158)$ & $1.091(0.163-7.308)$ \\
\hline \multicolumn{5}{|l|}{ Food Security Status } \\
\hline Food insecure & $46(31.9)$ & $98(68.1)$ & $1.486(0.711-3.108)$ & $1.345(0.594-3.044)$ \\
\hline Food secure & $12(24)$ & $38(76)$ & 1 & 1 \\
\hline
\end{tabular}

(1)




\section{Discussion}

This study intended to investigate the important interaction between risk factors and stunting among children age 24 to 59 months in Ende, East Nusa Tenggara. In general, the prevalence of stunting, zinc deficiency, anemia, nutrient inadequacy, and food insecurity were very high in children. We identified that serum ferritin have significance association with HAZ-score. We also found that household with more than four members and unsafe drinking water after controlling for confounders are the main independent factors that related to stunted children in rural area of Indonesia.

We observed the greater prevalence of anemia and iron deficiency among all child's participants. Further analysis showed $34 \%$ and $30.3 \%$ were anemic and iron deficient among stunted children. Interestingly, we found association between serum ferritin and HAZ-score (Table 2) and it was supported by our results that showed iron deficient children had two times risks to be stunted (Table 3). This finding was consistent with a systematic review in Ethiopia that pointed out poor dietary diversity, stunting, food insecurity, and not dewormed were predictors of anemic under-five children[25]. Food insecurity has consequences in both macro and micronutrient deficiencies that increased the risk of child anemia[26]. In fact, we identified high prevalence of household food insecurity (Table 1) and inadequacy of iron intake in our study (Supplementary table). Moreover, we found 19\% children infected with worm (Table 1), and one study demonstrated that helminths destroy red blood cells, reach hemoglobin and result in anemia in Ethiopian under-five children[25].

In this present analysis, we revealed weak association between serum zinc concentrations and HAZ-score but we found strong association between serum ferritin and HAZ-score (Table 2), suggesting that other factors might be playing more important role in the etiology of stunting than previously thought. Study in rural area of Guatemala explained the odds of being anemic were 3 times higher among zinc deficient children than those who were not and it was indicated the existence of multiple micronutrient deficiencies[27]. In our case, those given similar conditions were occurred in children age 24-59 months. The mechanism potentially linking zinc concentrations and HAZ-score is the presence of zinc deficiency reduced the lifespan of red blood cells due to the compromised function of zinc enzymes[28]. Then, it leads to iron deficiency, identifying have 2 times risks of being stunted children in our study (Table 3). Given these explanations, the interaction between parasitic infection, anemia, iron deficiency, and zinc deficiency and stunting is clearly determined.

According to WHO Conceptual Framework on Childhood Stunting[5], basic and underlying causes are the most affected factors of stunting in this study. Children living in rural communities had risk to suffer malnutrition more than in urban settings [7]. In our study, the selected setting was rural area with monthly expenses approximately IDR $600,000,--$ IDR 1,400,000,-. Moreover, household with $\geq 5$ members had 3 times risks to have stunted children after controlled by several factors (Table 3). It was consistent with previous studies in South Africa and Brazil that showed children living in big family $(\geq 5$ members) had 2-3 times more likely to develop stunting[29,30]. The poor condition led to lack of purchasing good of food quality, improper food allocation, limit access to adequate 
health services and WASH and it manifested to poor health condition[9,11,31]. In our current study, the percentage of household with food insecure was high (Table 1) and most of vitamin and minerals was inadequate (Supplementary table). In addition, children living with household food insecure had 1.3 times risks of being stunted after controlling for confounders (Table 3). This condition was related to poor household that contributed to high prevalence of stunting in Indonesia[6-9].

Our study highlights the emerging issue of child stunting in Eastern Indonesia. The data presented provides valuable insight into the prevalence of stunting in children which has remained fairly consistent in Indonesia over the last decade. Many specific and sensitive nutrition interventions implemented by Ministry of Indonesia should be improved in respond to specific problem in each condition. However, the observations of the study should be interpreted in the context of certain limitations. First, the crosssectional nature of this study means temporal relationship between stunting and its associated factors could not be established. Second, biochemical measurements and parasitical examination is only $50 \%$ of total sample so that it is not sufficient to include in logistic regression. Third, our present analysis did not use own's asset to define wealth index.

\section{Conclusions}

In summary, our findings indicate that the number of household members is the only independent risk factor of stunting among children age 24-59 months in rural area of Eastern Indonesia. Development of nutrition sensitive intervention on agriculture to improve food security especially for large-sized households might be needed in this area. Furthermore, promotion of family planning need to be emphasized in order to increase adequate child's care and feeding practices in rural area of Eastern Indonesia.

Supplementary Materials: Table 1. Percentage of nutrient inadequacy in underfive children.

Author Contributions: GW, UF, and TS conceived the study. DS, GW, EI, and TS trained and supervised the enumerators in the field. DS, GW, EI, UF, and TS implemented and interpreted the study. DS and EI conducted data cleaning. DS and GW provided data analysis and drafted the manuscript. UF and TS provided advice and revision of the final manuscript. All authors critically reviewed and approved the final manuscript.

Funding: The principal investigators disclosed receipt of the following financial support: Pintermidi Grant from Universitas Indonesia with contract number 1908/UN2.R3.1/HKP.05.00/2019.

Informed Consent Statement: Informed consent was obtained from all subjects involved in the study. Acknowledgments: We would like to express our gratitude to the study participants and the all team during data collection in Nangapada subdistrict for their significant contributions.

Conflicts of Interest: The author(s) declared no potential conflicts of interest with respect to the research, authorship, and/or publication of this article. 


\section{References}

1. Riskesdas, K. Hasil Utama Riset Kesehata Dasar (RISKESDAS). J. Phys. A Math. Theor. 2018, 44, 1-200, doi:10.1088/1751$8113 / 44 / 8 / 085201$.

2. $\quad$ Surveys, O.E. OECD Economic Surveys; 2007; ISBN 8889334207.

3. Black, R.E.; Victora, C.G.; Walker, S.P.; Bhutta, Z.A.; Christian, P.; De Onis, M.; Ezzati, M.; Grantham-McGregor, S.; Katz, J.; Martorell, R. Maternal and child undernutrition and overweight in low-income and middle-income countries. Lancet 2013, $382,427-451$.

4. Victora, C.G.; De Onis, M.; Hallal, P.C.; Blössner, M.; Shrimpton, R. Worldwide timing of growth faltering: revisiting implications for interventions. Pediatrics 2010, 125, e473-e480.

5. Stewart, C.P.; Iannotti, L.; Dewey, K.G.; Michaelsen, K.F.; Onyango, A.W. Contextualising complementary feeding in a broader framework for stunting prevention. Matern. Child Nutr. 2013, 9, 27-45.

6. Rachmi, C.N.; Agho, K.E.; Li, M.; Baur, L.A. Stunting, underweight and overweight in children aged 2.0-4.9 years in Indonesia: prevalence trends and associated risk factors. PLoS One 2016, 11, e0154756.

7. De Silva, I.; Sumarto, S. Child malnutrition in Indonesia: can education, sanitation and healthcare augment the role of income? J. Int. Dev. 2018, 30, 837-864.

8. Rizal, M.F.; van Doorslaer, E. Explaining the fall of socioeconomic inequality in childhood stunting in Indonesia. SSMpopulation Heal. 2019, 9, 100469.

9. Beal, T.; Tumilowicz, A.; Sutrisna, A.; Izwardy, D.; Neufeld, L.M. A review of child stunting determinants in Indonesia. Matern. Child Nutr. 2018, 14, e12617.

10. Torlesse, H.; Cronin, A.A.; Sebayang, S.K.; Nandy, R. Determinants of stunting in Indonesian children: evidence from a crosssectional survey indicate a prominent role for the water, sanitation and hygiene sector in stunting reduction. BMC Public Health 2016, 16, 669.

11. Titaley, C.R.; Ariawan, I.; Hapsari, D.; Muasyaroh, A.; Dibley, M.J. Determinants of the stunting of children under two years old in Indonesia: A multilevel analysis of the 2013 Indonesia Basic Health Survey. Nutrients 2019, 11, 1106.

12. Djuardi, Y.; Lazarus, G.; Stefanie, D.; Fahmida, U.; Ariawan, I.; Supali, T. Soil-transmitted helminth infection, anemia, and malnutrition among preschool-age children in Nangapanda subdistrict, Indonesia. PLoS Negl. Trop. Dis. 2021, 15, e0009506, doi:10.1371/journal.pntd.0009506.

13. Gunther, I.; Fink, G. Water, sanitation and children's health: evidence from 172 DHS surveys; The World Bank, 2010;

14. Coates, J.; Swindale, A.; Bilinsky, P. Household Food Insecurity Access Scale (HFIAS) for measurement of food access: indicator guide: version 3. 2007.

15. Harttig, U.; Haubrock, J.; Knüppel, S.; Boeing, H. The MSM program: web-based statistics package for estimating usual dietary intake using the Multiple Source Method. Eur. J. Clin. Nutr. 2011, 65, S87-S91.

16. Dary, O.; Hurrell, R. Guidelines on food fortification with micronutrients. World Heal. Organ. Food Agric. Organ. United Nations Geneva, Switz. 2006, 1-376.

17. Organization, W.H. WHO Anthro for personal computers manual: Software for assessing growth and development of the world's children; 2010;

18. Organization, W.H. WHO child growth standards: length/height-for-age, weight-for-age, weight-for-length, weight-for-height and body mass index-for-age: methods and development; World Health Organization, 2006; ISBN 924154693X.

19. Organization, W.H. Assessing the iron status of populations: report of a Joint World Health Organization/Centers for Disease Control and Prevention Technical Consultation on the Assessment of Iron Status at the Population Level, Geneva, Switzerland, 6-8 April 2004. In Assessing the iron status of populations: report of a Joint World Health Organization/Centers for Disease Control and Prevention Technical Consultation on the Assessment of Iron Status at the Population Level, Geneva, Switzerland, 
6-8 April 2004; 2005.

20. Hotz, C.; Brown, K.H. Assessment of the risk of zinc deficiency in populations and options for its control. 2004.

21. De Benoist, B.; Darnton-Hill, I.; Davidsson, L.; Fontaine, O.; Hotz, C. Conclusions of the joint WHO/UNICEF/IAEA/IZiNCG interagency meeting on zinc status indicators. Food Nutr. Bull. 2007, 28, S480-S484.

22. Thurnham, D.I.; McCabe, L.D.; Haldar, S.; Wieringa, F.T.; Northrop-Clewes, C.A.; McCabe, G.P. Adjusting plasma ferritin concentrations to remove the effects of subclinical inflammation in the assessment of iron deficiency: a meta-analysis. Am. J. Clin. Nutr. 2010, 92, 546-555.

23. Organization, W.H. Serum ferritin concentrations for the assessment of iron status and iron deficiency in populations; World Health Organization, 2011;

24. Dunn, J.C.; Turner, H.C.; Tun, A.; Anderson, R.M. Epidemiological surveys of, and research on, soil-transmitted helminths in Southeast Asia: a systematic review. Parasit. Vectors 2016, 9, 1-13.

25. Belachew, A.; Tewabe, T. Under-five anemia and its associated factors with dietary diversity, food security, stunted, and deworming in Ethiopia: systematic review and meta-analysis. Syst. Rev. 2020, 9, 31.

26. Habib, M.A.; Black, K.; Soofi, S.B.; Hussain, I.; Bhatti, Z.; Bhutta, Z.A.; Raynes-Greenow, C. Prevalence and predictors of iron deficiency anemia in children under five years of age in Pakistan, a secondary analysis of national nutrition survey data 2011-2012. PLoS One 2016, 11, e0155051.

27. Palacios, A.M.; Hurley, K.M.; De-Ponce, S.; Alfonso, V.; Tilton, N.; Lambden, K.B.; Reinhart, G.A.; Freeland-Graves, J.H.; Villanueva, L.M.; Black, M.M. Zinc deficiency associated with anaemia among young children in rural Guatemala. Matern. Child Nutr. 2020, 16, e12885.

28. Powell, S.R. The antioxidant properties of zinc. J. Nutr. 2000, 130, 1447S-1454S.

29. Menezes, R.C.E. de; Lira, P.I.C. de; Leal, V.S.; Oliveira, J.S.; Santana, S.C. da S.; Sequeira, L.A. de S.; Rissin, A.; Batista Filho, M. Determinants of stunting in children under five in Pernambuco, Northeastern Brazil. Rev. Saude Publica 2011, 45, 10791087.

30. Mamabolo, R.L.; Alberts, M.; Steyn, N.P.; Delemarre-van de Waal, H.A.; Levitt, N.S. Prevalence and determinants of stunting and overweight in 3-year-old black South African children residing in the Central Region of Limpopo Province, South Africa. Public Health Nutr. 2005, 8, 501-508.

31. Fikadu, T.; Assegid, S.; Dube, L. Factors associated with stunting among children of age 24 to 59 months in Meskan district, Gurage Zone, South Ethiopia: a case-control study. BMC Public Health 2014, 14, 800. 